\title{
COMPOSITION, ANTIFUNGAL ACTIVITY AND MAIN FUNGITOXIC COMPONENTS OF THE ESSENTIAL OIL OF MENTHA PIPERITA L.
}

\author{
MARCELO MOREIRA FREIRE ${ }^{1}$, GULAB NEWANDRAM JHAM ${ }^{2,5}$, ONKAR DEV DHINGRA ${ }^{2}$, \\ CAROLINA MARANGON JARDIM ${ }^{1}$, ROSIMEIRE COURA BARCELOS ${ }^{3}$ and \\ VÂNIA MARIA MOREIRA VALENTE ${ }^{4}$
}

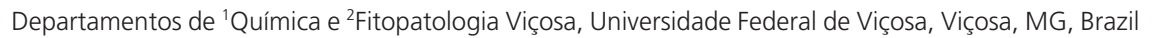

3Departamento de Química Orgânica, Instituto de Química, Universidade Estadual de Campinas, Campinas, SP, Brazil

${ }^{4}$ Campus de Rio Paranaíba, Universidade Federal de Viçosa, Rio Paranaíba, MG, Brazil

\begin{abstract}
${ }^{5}$ Corresponding author. TEL:
+55(31)3899-3071; FAX: +55(31)3899-3065; EMAlL: gulab@ufv.br
\end{abstract}

Received for Publication January 07, 2011

Accepted for Publication July 27, 2011

doi:10.1111/j.1745-4565.2011.00341.x

\begin{abstract}
Twenty-one components (93.9\% of the total chromatographic peak area) were tentatively identified in the essential oil (EO) of Mentha piperita L., based on Kováts retention indices (RIs), a mass spectral database (gas chromatography-mass spectrometry, GC-MS) and visual comparison of the mass spectra of the sample peaks with those of the database. The presence of 15 compounds (corresponding to $90.7 \%$ of the total chromatographic peak area) was confirmed by authentic standards. The EO presented a good activity against the following important postharvest deteriorating fungi: Aspergillus flavus, Aspergillus glaucus, Aspergillus niger, Aspergillus ochraceous, Colletotrichum gloesporioides, Colletotrichum musae, Fusarium oxysporum and Fusarium semitectum. At a concentration of $0.2 \%$ of the EO, all the fungi were completely inhibited, except for A. glaucus and C. musae which were inhibited 90 and $98 \%$, respectively. TLC-bioautography yielded three subfractions that prevented fungal growth, suggesting the presence of antifungals. Bioassay data of the crude EO were compared with those of the three subfractions. Based on these tests, it was concluded that several fungitoxics were responsible for the antifungal activity of $M$. piperita, with the principal ones being menthone, neomenthol, menthol and carvone. However, participation of other compounds cannot be ruled out. This is the first study in the literature that presents data on the activity of the crude EO against eight important postharvest deteriorating fungi, characterizing the amounts and types of comounds. In addition, also for the first time, the active fractions of the crude EO were isolated, identified and the components quantified. More detailed fungal tests are being conducted to confirm the tentative preliminary antifungal data.
\end{abstract}

\section{PRACTICAL APPLICATIONS}

Deterioration of agricultural products provoked by fungi accounts for considerable loss of crops of economic importance. Presently, these fungi are controlled by toxic synthetic chemicals. The food industry has significantly reduced the use of chemical preservatives. EOs have been known for their biological activities for many decades and they should, in principle, not be toxic to man and could replace toxic synthetic fungicides. This study demonstrates the potential of $M$. piperita EO as antifungal against C. gloeosporoides, C. musae, F. oxysporum, F. semitectum, A. niger, A. flavus and A. glaucus. Further studies are underway to evaluate M. piperita EO as a feed preservative. In addition, its principal active compounds were isolated and characterized. Identification of such components also helps to understand the mode of action of the extract, which can lead to the discovery of new antifungal compounds. 


\section{INTRODUCTION}

Deterioration of agricultural products provoked by fungi accounts for considerable loss of crops of economic importance (Ehlers et al.2006). Besides causing damage, some fungi produce mycotoxins, which are considered dangerous to human and animal health (Soković et al.2009). This problem is aggravated in warm and humid regions, ideal for fungi growth and mycotoxin production (Ehlers et al. 2006).

The food industry has significantly reduced the use of chemical preservatives (Tassou et al. 2000) because of their adverse effects (Soković et al. 2009). Consumers and legal authorities have pressured the food industry to either completely remove these toxic compounds or use natural food preservatives (Tassou et al.2000).

Biological activities of essential oils (EOs) have been known for many decades and are widely used as bactericidals, virucidals, fungicidals, antiparasiticals, insecticidals, cosmetics and pharmaceuticals (Dhingra et al. 2007; Bakkali et al. 2008; Van Vuuren et al.2009). EOs from edible plants, in principle, are not toxic and, thus, are potential food preservatives (Jardim et al. 2008).

Mentha genus, which includes approximately 30 species, is a perennial herb native to Europe, cultivated in the USA, Canada, Europe, Asia, Australia and South America (McKay and Blumberg 2006; Deschamps et al.2008). Mentha piperata EOs are used in flavors, fragrances and pharmaceuticals (İşcan et al. 2002; McKay and Blumberg 2006). M. piperita EOs have several important properties, such as antifungal (Schuhmacher et al. 2003; Matan et al. 2009; Soković et al. 2009), antiviral (Schuhmacher et al. 2003), antibacterial (İşcan et al. 2002; Schuhmacher et al. 2003; McKay and Blumberg 2006; Bakkali et al.2008; Rasooli et al.2008; Vuuren et al. 2009), insecticidal (Samarasekera et al. 2008), larvicidal and mosquito repellent, and are considered nontoxic for humans (Ansari et al.2000). M. piperita EO presents low mice toxicity, evidenced by high lethal dose $\left(\mathrm{LD}_{50}\right)$ value $(2,000 \mathrm{mg} / \mathrm{kg})$ (Debbab et al. 2007).

Identification of $M$. piperita EO components has been mostly based on Kováts retention indices (RIs) and a mass spectral database. However, such identification is tentative and must be confirmed by authentic standards. A very wide variation in the chemical composition (terpenes) of M. piperita has been reported (Ansari et al. 2000; İşcan et al. 2002; Dwivedi et al. 2004; Duarte et al. 2005; Debbab et al. 2007; Bakkali et al. 2008; Golebiowski et al. 2008; Rasooli et al. 2008; Matan et al. 2009; Soković et al. 2009).

Use of EO to protect agricultural products requires consistent performance, which can only be obtained if a preparation is standardized against an active fungitoxic component. Identification of active components also helps in understanding the mode of action of the extract, which can lead to the discovery of new antifungal compounds. However, major antifungals in M. piperita have not been isolated, characterized and quantified.

In this study we have: (1) tentatively identified the chemical composition of the crude $M$. piperita EO by RIs, a mass spectral database and by visual comparison of mass spectra of the samples peaks with that of the database. Tentative identifications were unequivocally confirmed by standards; (2) determined the activity of the crude $M$. piperita EO against the following eight major postharvest deteriorating fungi: Aspergillus flavus, Aspergillus glaucus, Aspergillus niger, Aspergillus ochraceous, Colletotrichum gloesporioides, Colletotrichum musae, Fusarium oxysporum and Fusarium semitectum; and (3) located the fungitoxic fraction by TLC-bioautography. In addition, the chemical compositions of the three sub fractions were determined along with their antifungal activities.

\section{MATERIALS AND METHODS}

\section{Plant Materials and Chemicals}

M. piperita leaves $(16 \mathrm{~kg}$ ), lot MENI09/02 of Polish origin were purchased from Santos Flora Comércio de Ervas Ltda (São Paulo, SP, Brazil). All solvents were of analytical grade (Vetec Química Fina, Rio de Janeiro, RJ, Brazil) and were distilled before use. Analytical thin layer chromatography (TLC) analyses were conducted on precoated silica gel plates $(5 \times 10 \mathrm{~cm}, 0.1-\mathrm{mm}$ thick, 60 GF254) while preparative TLC on precoated silica gel plates $(20 \times 20 \mathrm{~cm}, 1-\mathrm{mm}$ thick, 60 GF254). TLC plates were purchased from Merck, Rio de Janeiro, RJ, Brazil. Disposable Petri dishes $(60 \times 15 \mathrm{~mm}$ and $90 \times 15 \mathrm{~mm}$ ) and potato dextrose agar (PDA) were obtained from Prolab, Rio de Janeiro, RJ, Brazil. Standard 1,8-Cineole, menthone, neomenthol, menthol, terpin-4-ol, isomenthol, methyl chavicol, pulegone, carvone, menthyl acetate, eugenol (E)-caryophyllene, $\alpha$-terpineol and neomenthyl acetate were purchased from Sigma (St. Louis, MO, USA), and piperitone from Pfaltz \& Bauer (Waterbury, CT, USA).

\section{EO Extraction}

EO was obtained by hydrodistillation of shade-dried M. piperita leaves $(200 \mathrm{~g})$ with $1.4 \mathrm{~L}$ of distilled water $(1: 7 \mathrm{w} / \mathrm{v})$. The distillate $(1 \mathrm{~L})$ was extracted twice with dichloromethane $(5: 1 \mathrm{v} / \mathrm{v})$. The combined organic phases were dried with anhydrous sodium sulfate and filtered. Dichloromethane was evaporated in a rotary evaporator at $30 \mathrm{C}$, under reduced pressure. The $\mathrm{EO}$ was weighed, stored at $4 \mathrm{C}$ in sealed ampoules and used within a few days.

\section{Identification of the Compounds in the Crude EO}

Compounds in the crude EO were tentatively identified by RIs, a mass spectral database (Wiley/NBS Mass Spectral 
Registry) using similarity indices (SIs) and by visual comparison of the mass spectra of the peaks in the crude EO with those of the database. Only compounds with SIs of $90 \%$ or higher, provided by the gas chromatograph-mass spectrometer were considered as positive identifications. Tentative identifications were based on the best SI and RI fits (Adams 2007). The presence of 15 compounds was confirmed by standards. Further confirmation was based on spiking the crude EO with individual standards.

RIs data were obtained on a gas chromatograph with a flame ionization detector (Shimadzu, Kyoto, Japan; model GC $17 \mathrm{~A}$ ), an auto sampler and workstation. A mixture of linear saturated hydrocarbons and the crude EO were coinjected. The RIs were calculated from the following formula: $\mathrm{RI}=100 y+100(z-y) \times t_{\mathrm{R}(\mathrm{x})}-t_{\mathrm{R}(\mathrm{y})} / t_{\mathrm{R}(\mathrm{z})}-t_{\mathrm{R}(\mathrm{y})}$, where $y$ and $z$ are the carbon numbers in the hydrocarbons eluting before and after a gas chromatography (GC) peak of interest, respectively; $t_{\mathrm{R}(\mathrm{x})}$ is the retention time of the GC peak of interest; $t_{\mathrm{R}(\mathrm{y})}$ and $t_{\mathrm{R}(\mathrm{z})}$ are the retention times of the hydrocarbons, eluting before and after a GC peak of interest, respectively. Fused silica capillary column $(30 \mathrm{~m} \times 0.25 \mathrm{~mm}$; film thickness of $0.25 \mu \mathrm{m})$ coated with DB-5 stationary phase was purchased from Supelco (Bellefonte, PA, USA). The following conditions were used: oven temperature was programmed from $60 \mathrm{C}$ ( $1 \mathrm{~min}$ hold) to $240 \mathrm{C}$ ( $9 \mathrm{~min}$ hold) at $3 \mathrm{C} / \mathrm{min}$; the injector and detector were maintained at 240 and $250 \mathrm{C}$, respectively. Nitrogen was the carrier gas at a flow rate of $1.3 \mathrm{~mL} / \mathrm{min}$.

Mass spectral data were obtained on a gas chromatographmass spectrometer (Shimadzu; model QP 5000 and software program-Classs-5000, Version 1.2), fitted with an auto sampler, workstation and a database with around 350,000 entries. Conditions described for GC analysis were also used for GC-mass spectrometry (GC-MS) with the transfer line at $250 \mathrm{C}$ with helium as the carrier gas (flow rate of $1.3 \mathrm{~mL} / \mathrm{min}$ ). The mass spectrometer was scanned from $\mathrm{m} / \mathrm{z} 40$ to 350 in the electron impact mode $(70 \mathrm{eV})$. To obtain representative data, mass spectra over the entire GC peaks ( $\sim 10$ scans) of interest were grouped and subtracted from the grouped mass spectra of the region closest (before or after) to where no compound eluted ( $\sim 50$ scans). For GC and GC-MS analysis, $1-\mu \mathrm{L}$ of the crude EO dissolved in hexane (10\%) was injected by the split mode (1:20), with the split vent being closed for $30 \mathrm{~s}$.

\section{Test Fungi}

The fungal isolates used in this study are deposited in the mycological collection of the Department of Phytopathology of the Federal University of Viçosa. A. flavus Link (Moniliales), strain AFM 4; A. glaucus Teleomorph Eurotium herbariorumm (Wiggers) Link, strain AGM 9; A. niger van Tieghem (Moniliales), strain ANM 6; and A.ochraceous Wilhelm (Moniliales), strain AOM 18, were isolated from maize seed. C. gloesporioides (Penz.) Sacc. (Melanoconiales), strain CGP 14 and C. musae (Berk. \& Curt.) Arx (Melanoconiales), strain $\mathrm{CMB} 6$, were isolated from papaya and banana fruit, respectively. F. oxysporum Schlecht. Fr. (Moniliales), strain FSB 7, and F. semitectum Wollenw (Moniliales), strain FOB 11, were isolated from bean root and seed, respectively.

\section{Antifungal Activity}

EO activity was tested on PDA, using the poison food assay (Dhingra and Sinclair 1995). The antifungal potential of the crude EO was evaluated at concentrations of 0.1 and $0.2 \%$ $(\mathrm{v} / \mathrm{v})$. The EO was dissolved in Tween $20(0.1 \% \mathrm{v} / \mathrm{v})$ and added to molten PDA (35C) together with streptomycin sulphate. Ten milliliters of the medium was poured into $9-\mathrm{cm}$ culture plates. The medium in each plate was spot-seeded with each of the test fungus conidia. The colony diameter was measured after 7 days of incubation at 25C. All tests were carried out in triplicate. Inhibition percentage (IP) was calculated according to the equation: $\% \mathrm{IP}=100-[(100 \times B) / A]$, where $A$ and $B$ are the radial growth inhibitions of the control and the sample, respectively. Blanks were run in exactly the same manner without the EO.

\section{Identification of the Fungitoxic Fraction of the EO, Determination of its Antifungal Activity and Chemical Composition}

To identify the antifungal fraction of M. pipertia, the crude EO was fractionated by TLC-bioautography (Rahalison et al. 1991; Wedge and Nagle 2000). The crude EO (75 mg dissolved in $0.5 \mathrm{~mL}$ of dichloromethane) was coated horizontally as a narrow streak about $2 \mathrm{~cm}$ above the base of a preparative silica gel TLC plate $(20 \times 20 \mathrm{~cm})$ using a disposable Pasteur pipette. The TLC plate was placed in a transparent glass chamber and eluted with dichloromethane: hexane $(2: 1 \mathrm{v} / \mathrm{v})$ as the solvent. After elution, the plate was removed from the development chamber, placed on a clean metal tray and allowed to dry for several minutes. After evaporation of the solvent, molten PDA containing streptomycin sulfate and conidia $\left(10^{3} / \mathrm{mL}\right)$ of $A$. flavus was sprayed over the plate and incubated for 7 days at $25 \mathrm{C}$ in a moisture-saturated plastic box. The bands on the TLC were visualized under ultraviolet (UV) light or by spraying with a solution (about $5 \mathrm{~mL}$ ) of vanillin and concentrated sulfuric acid (prepared by dissolving $15 \mathrm{~g}$ of vanillin in $250 \mathrm{~mL}$ of ethanol, followed by the addition of $2.5 \mathrm{~mL}$ of concentrated sulfuric acid). Visualized bands were arbitrarily designated as $\mathrm{SF}_{1}, \mathrm{SF}_{2}$ and $\mathrm{SF}_{3}$ (lowest to highest retention factor $\left.\left[\mathrm{R}_{f}\right]\right)$. The area on the TLC plate with no fungus development, considered to contain antifungals was delineated and the $\mathrm{R}_{f}$, along with the longitudinal width $(\mathrm{Lw})$ were measured. A total of 63 plates were coated with the crude EO and worked up in exactly the same manner. 
Appropriate bands from all the plates containing the fungitoxic fractions were scraped, pooled, extracted with two portions of dichloromethane ( $250 \mathrm{~mL}$ each), filtered, dehydrated with anhydrous sodium sulfate and filtered. The solvent was evaporated in a rotary evaporator at room temperature; the residues were weighed and stored at $4 \mathrm{C}$ until use. For identification, the residues were redissolved in dichloromethane and analyzed by GC and GC-MS. The antifungal activity and the chemical composition of the fungitoxic fraction were determined as described for the crude EO. Blanks were run in exactly the same manner without the EO.

\section{RESULTS}

\section{EO Yield and Chemical Composition}

Hydrodistillation of the M. piperita dry leaves yielded $0.6 \%$ (w/w) of the EO. Twenty-one components (93.8\% of the total chromatographic peak area) were tentatively identified in the crude EO, based on RIs, mass spectral database and by visual comparison of the mass spectra of the sample peaks with those of the database (Fig. 1, Table 1).Although 21 compounds were tentatively identified by RIs and a mass spectral database, the
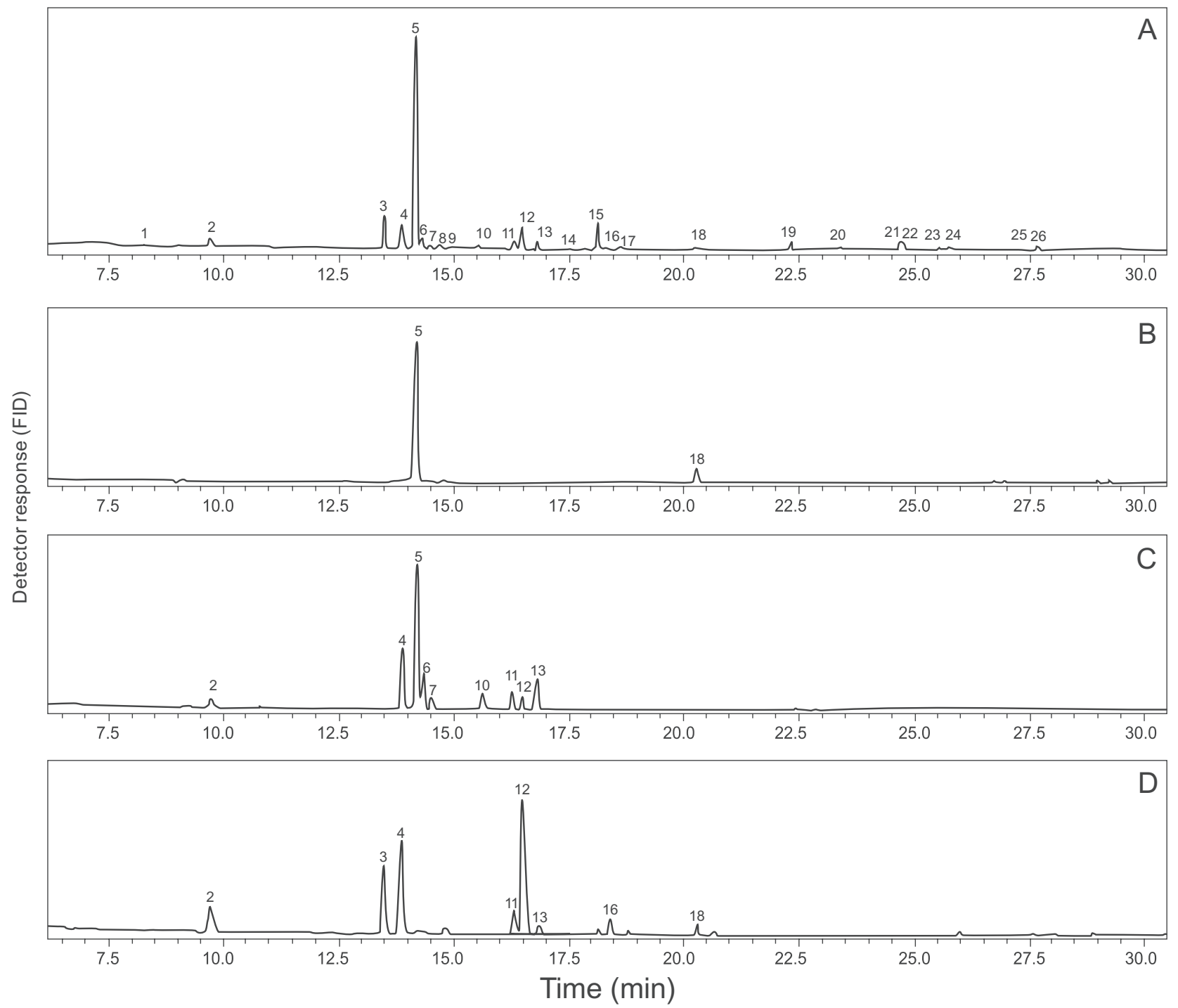

FIG. 1. GAS CHROMATOGRAM OBTAINED ON THE ANALYSIS OF CRUDE ESSENTIAL OIL (A) AND PURIFIED SUBFRACTIONS SF 1 (B), SF 2 (C) AND SF 3 (D) OF MENTHA PIPERITA L.

Chromatography conditions: oven temperature programmed from 60C (1 min hold) to $240 \mathrm{C}$ (9 min hold) at 3C/min; $\mathrm{N}_{2} \mathrm{Carrier}$ gas (1.3 mL/min), temperatures of injector and a flame ionization detector 220 and $240 \mathrm{C}$, respectively, fused silica capillary column coated with a DB-5 stationary phase. Peaks identified in the chromatograms refer to the compounds listed and numbered in Table 1. 
TABLE 1. PERCENT COMPOSITION OF THE CRUDE ESSENTIAL OIL AND ACTIVE SUBFRACTIONS SF $1, \mathrm{SF}_{2}$ AND SF $\mathrm{SF}_{3}$ OF MENTHA PIPERITA L. BASED ON KOVÁTS RETENTION INDEXES, GAS CHROMATOGRAPHY-MASS SPECTROMETRY AND VISUAL COMPARISON OF THE MASS SPECTRA OF THE SAMPLE PEAKS WITH THOSE OF THE DATABASE AND AUTHENTIC STANDARDS

\begin{tabular}{|c|c|c|c|c|c|c|}
\hline \multirow[b]{3}{*}{ Peak no (Fig. 1) } & \multirow{3}{*}{$\begin{array}{l}\text { Retention } \\
\text { index (RI) }\end{array}$} & \multirow[b]{3}{*}{ Compound } & \multicolumn{4}{|c|}{ Percent composition (\%) } \\
\hline & & & \multirow[b]{2}{*}{ Crude EO } & \multicolumn{3}{|c|}{ Fungitoxic subfractions } \\
\hline & & & & $\mathrm{SF}_{1}$ & $\mathrm{SF}_{2}$ & $\mathrm{SF}_{3}$ \\
\hline 1 & 978 & Octen-3-ol & 0.7 & - & - & - \\
\hline 2 & 1,033 & 1,8-Cineole & $2.6^{*}$ & - & 1.4 & 6.8 \\
\hline 3 & 1,154 & Menthone & $7.3^{*}$ & - & - & 15.0 \\
\hline 4 & 1,165 & Neomenthol & $6.3^{*}$ & - & 16.4 & 24.4 \\
\hline 5 & 1,173 & Menthol & $54.2^{*}$ & 88.3 & 47.5 & - \\
\hline 6 & 1,177 & Terpin-4-ol & $1.7^{*}$ & - & 5.7 & - \\
\hline 7 & 1,182 & Isomenthol & $0.9 *$ & - & 1.9 & - \\
\hline 8 & 1,188 & $\alpha$-Terpineol & $1.3^{*}$ & - & - & - \\
\hline 9 & 1,195 & Methyl chavicol & $0.7^{*}$ & - & - & - \\
\hline 10 & - & Oct-7-en-1-yl acetate & 1.1 & - & 2.5 & - \\
\hline 11 & 1,237 & Pulegone & $1.8^{*}$ & - & 2.8 & 5.3 \\
\hline 12 & 1,242 & Carvone & $5.0^{*}$ & - & 2.0 & 35.5 \\
\hline 13 & 1,252 & Piperitone & $1.5^{*}$ & - & 5.5 & 1.8 \\
\hline 14 & 1,275 & Neomenthyl acetate & $0.5^{*}$ & - & - & - \\
\hline 15 & 1,294 & Menthyl acetate & $4.0^{*}$ & - & - & - \\
\hline 16 & 1,306 & Iso menthyl acetate & 0.2 & - & - & 2.9 \\
\hline 17 & 1,348 & 4-Methoxyacetophenone & 0.2 & - & - & - \\
\hline 18 & 1,356 & Eugenol & $0.4^{*}$ & 4.3 & - & 1.6 \\
\hline 19 & 1,418 & (E)-Caryophyllene & $2.4^{*}$ & - & - & - \\
\hline 20 & 1,458 & (E)- $\beta$-Farnesene & 0.5 & - & - & - \\
\hline 21 & 1,507 & $?$ & 2.0 & 4.0 & 8.1 & 3.4 \\
\hline \multirow[t]{2}{*}{22} & 1,524 & $\delta$-Cadinene & 0.5 & 3.4 & - & 0.8 \\
\hline & & Total identified & $93.9\left(90.7^{*}\right)$ & 100 & 93.8 & 97.5 \\
\hline
\end{tabular}

* Confirmed by authentic standards. presence of the following 15 compounds (corresponding to $90.7 \%$ of the total chromatographic peak area) was confirmed by authentic standards (elution order): 1,8-cineole, menthone, neomenthol, menthol, terpin-4-ol, isomenthol, $\alpha$-terpineol, methyl chavicol, pulegone, carvone, piperitone, neomenthyl acetate, menthyl acetate, eugenol and $(E)$ caryophyllene. Menthol, menthone, neomenthol, carvone and menthyl acetate corresponded to $76.9 \%$ of the peak area, while the remaining $19 \%$ of the peak area was made up by 16 constituents with relative concentrations less than $3.0 \%$.

The crude EO inhibited the growth of all the eight test fungi at concentrations of 0.1 and $0.2 \%$ (Fig. 2A). At $0.1 \%$, all fungi were moderately inhibited, ranging from $44.1 \%$ (A. niger) to $85.4 \%$ (F. oxysporum), except for C. gloeosporioides, where the inhibition was only $17.4 \%$. The crude EO completely inhibited the radial growth of all fungi at a concentration of $0.2 \%$, except A. glaucus and C. musae (90 and 98\% inhibition, respectively).

Fractionation of the crude EO by TLC-biautobiography yielded three bands without fungal growth. $\mathrm{R}_{f}$ of the subfractions $\mathrm{SF}_{1}, \mathrm{SF}_{2}$ and $\mathrm{SF}_{3}$ was $0.47,0.60$ and 0.68 , respectively. $\mathrm{Lw}$ of the subfractions $\mathrm{SF}_{1}, \mathrm{SF}_{2}$ and $\mathrm{SF}_{3}$ was $8,0.5$ and $1.0 \mathrm{~cm}$, respectively. Bands $\mathrm{SF}_{1}$ and $\mathrm{SF}_{2}$ could be visualized under a UV lamp while the band $\mathrm{SF}_{3}$ only after spraying with a solution of sulphuric acid and vanillin. On GC analysis, the subfractions $\mathrm{SF}_{1}, \mathrm{SF}_{2}$ and $\mathrm{SF}_{3}$ presented one, two and three major components, respectively (Fig. 1, Table 1). In the subfractions $\mathrm{SF}_{1}, \mathrm{SF}_{2}$ and $\mathrm{SF}_{3}$, the principal components (\%) were menthol (88.3), neomenthol (16.4) and menthone (15.0), neomenthol (24.4) and carvone (35.5), respectively.

All the eight fungi were sensitive to the active subfractions at the concentration of $0.1 \%$ (Fig. $2 \mathrm{~B}$ ). Subfraction $\mathrm{SF}_{1}$ was more active against A. flavus, A. niger, F. oxysporum, and F. semitectum, while $\mathrm{SF}_{2}$ and $\mathrm{SF}_{3}$ were more fungitoxic to A. glaucus, C. musae, F. oxysporum and F. semitectum.

\section{DISCUSSION}

\section{EO Yield}

Yield of $M$. piperita $(0.60 \%)$ EO in this study was similar to that reported by other authors. Yields of $0.40,0.50$ and $0.70 \%$ of the peppermint EO were reported from India (Ansari et al. 2000; Dwivedi et al. 2004). Brazilian cultivars from Paraná yielded $0.15-0.67 \%$ in summer and $0.05-$ $0.45 \%$ in winter (Deschamps et al. 2008), while the cultivars from São Paulo (Brazil) yielded 0.42 (Sartoratto et al. 2004) and $0.8 \%$ (Duarte et al. 2005). Plants grown in Morocco yielded $1.72 \%$ of EO (Debbab et al. 2007). Variation in EO 


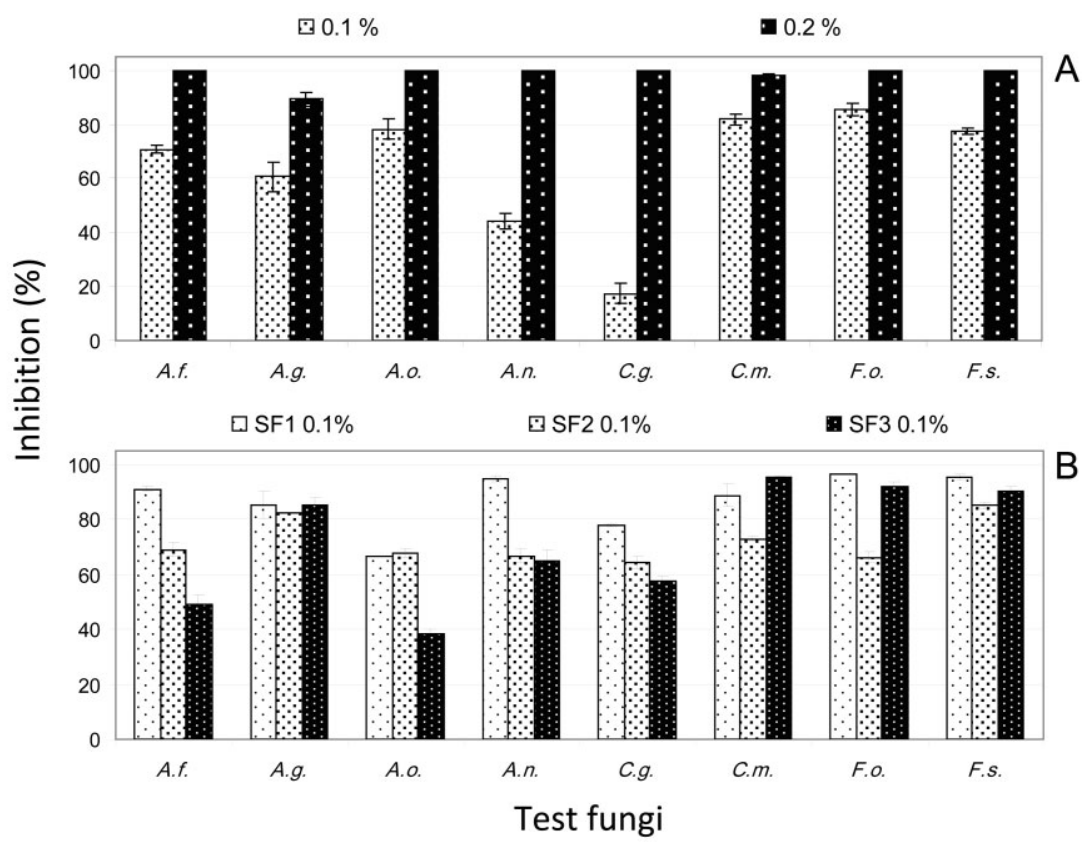

FIG. 2. PERCENT RADIAL GROWTH INHIBITED BY CRUDE ESSENTIAL OIL (EO) OF MENTHA PIPERITA L. AT CONCENTRATIONS OF 0.1 AND 0.2 (A) AND PURIFIED SUBFRACTIONS ( $\mathrm{SF}_{1}, \mathrm{SF}_{2}$ AND $\mathrm{SF}_{3}$ ) OF M. PIPERITA EO AT 0.1\% (B) AFTER 7-DAY INCUBATION AT 25C Mean of three replications. The bars represent standard deviation within the treatment. A.f., Aspergillus flavus; A.g., Aspergillus glaucus; A.n., Aspergillus niger; A.o., Aspergillus ochraceous; C.g., Colletotrichum gloesporioides; C.m., Colletotrichum musae; F.o., Fusarium oxysporum; F.s., Fusarium semitectum. yield and its chemical composition was expected as they are affected by several factors, such as genotype, agroclimatic conditions, fertilization, plant organ, age and vegetative cycle stage (Gobbo-Neto and Lopes 2007; Bakkali et al. 2008).

\section{Chemical Composition of the EO}

Since the crude EO presented a complex chromatogram, identification of components based on RIs, mass spectral database and by visual comparison of the mass spectra of the sample peaks with those of the database would not be reliable. Hence, this identification was followed by confirmation by standards. The presence of 15 compounds (corresponding to $90.7 \%$ of the total chromatographic area) was confirmed by standards (Table 1, Fig. 1). It is interesting to note that all the compounds identified tentatively based on both the RI and the database were confirmed by standards. Despite this agreement, it must be pointed out that MS database identifications are considered tentative since they depend on several factors, such as chromatographic conditions, database used and the type of the mass spectrometer. In addition, RIs are known to vary slightly with chromatographic conditions, particularly the age of chromatographic column.

Most of the components identified in the M. piperita EO were monoterpenes, the main components (in \%) being menthol (54.2), followed by menthone (7.3), neomenthol (6.3), carvone (5.0) and menthyl acetate (4.0). The following components (\%) have been identified in the M. piperita EO: menthol (33-60), menthone (15-32), isomenthone (2-8), 1,8-cineole (5-13), menthyl acetate (2-11), menthofuran
(1-10), limonene $(1-7), \quad \beta$-myrcene $\quad(0.1-1.7), \quad \beta$ caryophyllene (2-4), pulegone (0.5-1.6) and carvone (1) (McKay and Blumberg 2006). Accession of M. piperita from India presented menthol (29.8-37.3), p-menthone (27.133.0 ), isomenthone (4.4-8.5), pulegone (0.2-7.5), menthyl acetate (1.6-4.3), cineole (0.5-6.5) (Dwivedi et al. 2004). Menthol and menthone were major components in the M. piperita EO from Turkey, U.S.A., India, Germany, Sri Lanka, Argentina and Poland, presenting the following percentage composition: 27.5 and 27.9, 42.3 and 21.1, 34.6 and 18.4, 42.8 and 14.6, 41.2 and 24.3, 41.5 and 20.9, and 49.4 and 23.5, respectively (İşcan et al. 2002; Schuhmacher et al. 2003; Golebiowski et al. 2008; Samarasekera et al. 2008; Palacios et al. 2009). Menthol was the major component of the M. piperita EO from Thailand (61\%) and India (81.1\%) (Ansari et al. 2000; Matan et al. 2009); while in EO from Serbia, the main components (\%) were menthol (37.4), menthyl acetate (17.4) and menthone (12.7), respectively (Soković et al. 2009). However, in the Brazilian EO the percentage of linalool, 3 -octanol and carvone was 51, 10.1 and 23.4\%, respectively, while menthone, isomenthone, menthyl acetate, neomenthol and menthol were not detected (Duarte et al. 2005). In the peppermint EO from Portugal, menthol was not detected, with linalyl acetate (72\%) and linalool (12.3\%) being the main compounds (Martins et al. 2004), EO from Iran contained $\alpha$-terpinene $(19.7 \%)$, isomenthone $(10.3 \%)$, trans carveol (14.5\%), pipertitinone oxide (19.3\%) and $\beta$-caryophyllene (7.6\%) (Rasooli et al. 2008). The major compounds (\%) characterized in M. piperita $\mathrm{EO}$ grown in Morocco were linalool (60.7), linalyl acetate (20.7), geraniol (3.2), 1,8-cineol (2.3) and limonene (1.5) (Debbab et al. 
2007). However, the chemical composition reported in many literature studies have used only RI and a mass spectral database for identification of EO components (İşcan et al. 2002; Sridhar et al. 2003; Dwivedi et al. 2004; Sartoratto et al. 2004; Duarte et al. 2005; Soković et al. 2009). While these techniques are widely used and very convenient, they are not reliable, and the final identification must be confirmed by authentic standards.

Results on fractionation of $M$. piperita EO have not been reported and, hence, it will not be possible to compare our results with those of the literature. The chemical composition of the three subfractions was based on RIs, mass spectral database and by visual comparison of the mass spectra of the sample peaks with those of the database. In addition, identification was based on comparison of $t_{R}$ and $r t_{R}$ of peaks in the three subfractions with those of the crude EO, where several peaks were confirmed with authentic standards.

\section{Antifungal Activity}

Crude M. piperita EO inhibited the growth of all the eight test fungi. The sensitivity of the test fungi to the M. piperita $\mathrm{EO}$ at a concentration of $0.1 \%$ differed significantly. The most susceptible fungus was F. oxysporum with $85 \%$ inhibition, and the least senstive was C. gloeosporioides, with $17 \%$ inhibition. Percentage inhibition increased with the concentration. At a concentration of $0.1 \%$, all the fungi were moderately inhibited, while at a concentration of $0.2 \%$, the crude EO completely inhibited the radial growth of all fungi, except for A. glaucus and $C$. musae, which were, respectively, 90 and $98 \%$ inhibited.

The effectiveness of $M$. piperita EO as an antifungal agent against 17 micromycetal food poisoning, plant, animal and human pathogens was reported by Soković et al. (2009). Mentha sp. showed strong antifungal activity, higher than bifonazole (commercial fungicide used as a control) but lower than that of pure menthol. Carvone presented the best antifungal properties. At a concentration of $0.1 \%$, the EO totally inhibited A. flavus in corn (Belmont and Carvajal 1998). M. piperita drastically reduced viable cells of Staphylococcus aureus, a foodborne bacteria, suggesting that the EO oil can be a promising preservative for some foods (Tassou et al. 2000). However, the chemical composition of this EO was not determined.

At $0.1 \%$, antifungal activity of the subfractions depended on the fungus. For example, for the fungi A. flavus, A. niger and C.gloesporioides, the activities increased as follows: $\mathrm{SF}_{1}>\mathrm{SF}_{1}>\mathrm{SF}_{1}$; for A. glaucus, the antifungal activities were essentially the same (Fig. 2B). The EO activity probably could be attributed to menthol, considering that, generally, their biological properties are determined by the major components (Bakkali et al.2008). In addition, menthol was the main inhibitory component of $M$. piperita $\mathrm{EO}$ against the fungus Trametes versicolor (Matan et al. 2009). This observation is coherent with the fact $M$. piperita EO from Brazil, containing high amount of linalool (51\%), but no menthol, had only a moderate activity (minimal inhibition concentration [MIC] $0.6 \mathrm{mg} / \mathrm{mL}$ ) against Candida albicans (Duarte et al. 2005). Bioautography assay against C. albicans suggested that menthol was responsible for the antimicrobial activity of the EO obtained from commercial sources (İşcan et al. 2002). However, further tests must be conducted before attributing the activity of $M$. piperita $\mathrm{EO}$ to menthol.

The subfraction $\mathrm{SF}_{2}$ was constituted mainly of menthol (47.5\%) and neomenthol (16.4\%), both antifungal compounds (Niridy 1998). However, menthol was not detected in the subfraction $\mathrm{SF}_{3}$, which had carvone, neomenthol and menthone as main constituents $(35.5,24.4$ and $15.0 \%$, respectively), compounds with an antifungal activity (Niridy 1998; Sridhar et al. 2003; Soković et al. 2009). According to Niridy (1998), menthol, neomenthol, menthyl acetate, menthone and linalool inhibited the mycelial growth of $C$. gloesporioides.

Although the chemical identifications of the crude EO and the active fraction are unequivocal, the antifungal activity tests in this study are still preliminary. Other antifungal tests (broth, diffusion and disc), including EO effects on more fungal strains of the same genera/species and maximal effective concentration (EC50) with pure standards will be conducted. Such studies would be beyond the scope of this study but will be reported in other communications. Despite these limitations, this is the first study in the literature where the chemical composition of the Brazilian M. piperita EO was unequivocally determined simultaneously with antifungal activity and isolation/characterization of the active fraction. The information generated in this study will be useful for further studies in our laboratory, as well as to scientists worldwide.

\section{ACKNOWLEDGMENTS}

We thank Coordenação de Aperfeiçoamento de Pessoal de Nível Superior (CAPES) and Conselho Nacional de Pesquisa (CNPq) for granting scholarships to the authors and to the technician Mr. Eduardo Pereira Rezende. This work was supported, in part from grants from Fundação de Amparo à Pesquisa do Estado de Minas Gerais (FAPEMIG).

\section{REFERENCES}

ADAMS, R.P. 2007. Identification of Essential Oil Components by Gas Chromatography/Mass Spectroscopy, Allured, Carol Stream, IL.

ANSARI, M.A., VASUDEVAN, P., TANDON, M. and AZDAN, R.K. 2000. Larvicidal and mosquito repellent action of peppermint (Mentha piperita) oil. Bioresour. Technol. 71, 267-271. DOI:10.1016/S0960-8524(99)00079-6.

BAKKALI, F., AVERBECK, S., AVERBECK, D. and IDAOMAR, M. 2008. Biological effects of essential oils - a review. Food Chem. Toxicol. 46, 446-475. DOI:10.1016/j.fct.2007.09.106. 
BELMONT, R.M. and CARVAJAL, M. 1998. Control of Aspergillus flavus in maize with plant essential oils and their components. J. Food Prot. 61, 616-619.

DEBBAB, A., MOSADDAK, B., ALY, A.H., HAKIKI, A. and MOSADDAK, M. 2007. Chemical characterization and toxicological evaluation of the essential oil of Mentha piperita L. growing in Morocco. Sci. Study Res. 8, 281-288.

DESCHAMPS, C., ZANATTA, J.L., BIZZO, H.R., OLIVEIRA, M.C. and ROSWALKA, L.C. 2008. Seasonal evaluation of essential oil yield of mint species. Ciênc. Agrotec. 32, 725-730.

DHINGRA, O.D. and SINCLAIR, J.B. 1995. Basic Methods in Plant Pathology, CRC press, Boca Raton, FL.

DHINGRA, O.D., JHAM, G.N., BARCELOS, R.C., MENDOÇA, F.A. and GHIVIRIGA, I. 2007. Isolation and identification of the principal fungitoxic component of turmeric essential oil. J. Essent. Oil Res. 19, 387-391.

DUARTE, M.C.T., FIGUEIRA, G.M., SARTORATTO, A., REHDER, V.L.G. and DELARMELINA, C. 2005. Anti-Candida activity of Brazilian medicinal plants. J. Ethnopharmacol. 97, 305-311.

DWIVEDI, S., KHAN, M., SRIVASTAVA, S.K., SYAMASUNNDER, K.V. and SRIVASTAVA, A. 2004. Essential oil composition of different accessions of Mentha piperita L. grown on the northern plains of India. J. Flavour Frag. 19, 437-440.

EHLERS, D., CZECH, E., QUIRIN, K.W. and WEBER, R. 2006. Distribution of aflatoxins between extract and extraction residue of paprika using supercritical carbon dioxide. Phytochem. Anal. 17, 114-120. DOI:10.1002/pca.894. GOBBO-NETO, L. and LOPES, N.P. 2007. Plantas medicinais: Fatores de influência no conteúdo de metabólitos secundários. Quim. Nova 30, 374-381.

GOLEBIOWSKI, M., OSTROWSKI, B., PASZKIEWICZ, M., CZERWICKA, M., KUMIRSKA, J., HALINSKI, L., MALINSKI, E. and STEPNOWSKI, P. 2008. Chemical composition of commercially available essential oils from blackcurrant, ginger and peppermint. Chem. Nat. Compd. 44, 794-796. DOI:10.1007/s10600-009-9171-y.

İŞCAN, G., KİRIMMER, N., KÜRKCÜOĞLU, M., BAŞER, K.H.C. and DEMIRCİ, F. 2002. Antimicrobial screening of Mentha piperita essential oils. J. Agric. Food Chem. 50, 3943-3946.

JARDIM, C.M., JHAM, G.N., DHINGRA, O.D. and FREIRE, M.M. 2008. Composition and antifungal activity of the essential oil of the Brazilian Chenopodium ambrosioides L.

J. Chem. Ecol. 34, 1213-1218. DOI:10.1007/s10886-008-9526-Z.

MARTINS, M.M., COSTA, S.B., NEVES, C., CAVALEIRO, C., SALGUEIRO, L. and COSTA, M.L.B. 2004. Olive oil flavoured by the essential oils of Mentha piperita and Thymus mastichina L. Food Qual. Prefer. 15, 447-452.

MATAN, N., WORAPRAYOTE, W., SAENGKRAJANG, W., SIRISOMBAT, N. and MATAN, N. 2009. Durability of rubberwood (Hevea brasiliensis) treated with peppermint oil, eucalyptus oil, and their main components. Int. Biodeter. Biodegr. 63, 621-625. DOI: 10.1186/1471-2180-10-282.
MCKAY, D.L. and BLUMBERG, J.B.A. 2006. Review of the bioactivity and potential health benefits of peppermint tea (Mentha piperita L.). Phytother. Res. 20, 619-633. DOI:10.1002/ptr.1936.

NIRIDY, E.S.J. 1998. Structure-fungitoxicity relationships of the monoterpenoids of the oils of peppermint (Mentha piperita) and scented geranium (Pelargonium graveolens). J. Essent. Oil Res. 10, 628-631.

PALACIOS, S.M., BERTONI, A., ROSSI, Y., SANTANDER, R. and URZÚA, A. 2009. Efficacy of essential oils from edible plants as insecticides against the house fly, Musca domestica L. Molecules 14, 1938-1947. DOI:10.3390/molecules14051938.

RAHALISON, L., HAMBURGER, M., HOSTETTMANN, K., MONOD, M. and FRENK, E.A. 1991. Bioautographic agar overlay method for the detection of antifungal compounds from higher plants. Phytochem. Anal. 2, 199-203. DOI:10.1002/pca.2800020503.

RASOOLI, I., GACHKAR, L., YADEGARINIA, D., REZAEI, M.B. and ALIPOOR ASTANEH, S.D. 2008. Antibacterial and antioxidative characterization of essential oils from Mentha piperita and Mentha spicata grown in Iran. Acta. Aliment. 37, 41-52.

SAMARASEKERA, R., WEERASINGHE, I.S. and HEMALAL, K.D.P. 2008. Insecticidal activity of menthol derivatives against mosquitoes. Pest Manag. Sci. 64, 290-295.

DOI:10.1002/ps.1516.

SARTORATTO, A., MACHADO, A.L.M., DELARMELINA, C., FIGUEIRA, G.M., DUARTE, M.C.T. and REHDER, V.L.G. 2004. Composition and antimicrobial activity of essential oils from aromatic plants used in Brazil. Braz. J. Microbiol. 35, 275-280. DOI:10.1590/S1517-83822004000300001.

SCHUHMACHER, A., REICHLING, J. and SCHNITZLER, P. 2003. Virucidal effect of peppermint oil on the enveloped viruses herpes simplex virus type 1 and type 2 in vitro. Phytomedicine 10, 504-510.

SOKOVIĆ, M.D., VUKOJEVIĆ, J., MARIN, P.D., BRKIĆ, D.D. VAJS, V. and GRIENSVEN, L.J.L.D. 2009. Chemical composition of essential oils of Thymus and Mentha species and their antifungal activities. Molecules 14, 238-249.

SRIDHAR, S.R., RAJAGOPAL, R.V., RAJAVEL, R., MASILAMANI, S. and NARASIMHAN, S. 2003. Antifungal activity of some essential oils. J. Agric. Food Chem. 51, 7596-7599. DOI:10.1021/jf0344082.

TASSOU, C., KOUTSOUMANIS, K. and NYCHAS, G.J.E. 2000. Inhibition of Salmonella enteritidis and Staphylococcus aureus in nutrient broth by mint essential oil. Food Res. Int. 33, 273-280. DOI:10.1016/S0963-9969(00)00047-8.

VAN VUUREN, S.F., SULIMAN, S. and VILJOEN, A.M. 2009. The antimicrobial activity of four commercial essential oils in combination with conventional antimicrobials. Lett. Appl. Microbiol. 48, 440-446. DOI: 10.1111/j.1472-765X.2008.02548.x.

WEDGE, D.E. and NAGLE, D.G.A. 2000. New 2D-TLC bioautography method for the discovery of novel antifungal agents to control plant pathogens. J. Nat. Prod. 63, 1050-1054. DOI:10.1021/np990628r. 